\title{
A model of hemorrhagic cystitis induced with acrolein in mice
}

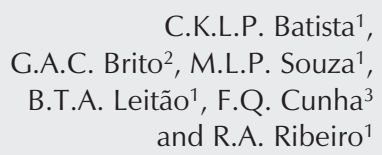

C.K.L.P. Batista ${ }^{1}$

G.A.C. Brito ${ }^{2}$, M.L.P. Souza ${ }^{1}$,

B.T.A. Leitão ${ }^{1}$, F.Q. Cunha ${ }^{3}$ and R.A. Ribeiro ${ }^{1}$

\author{
${ }^{1}$ Departamento de Fisiologia e Farmacologia, ${ }^{2}$ Departamento de Morfologia, \\ Faculdade de Medicina, Universidade Federal do Ceará, Fortaleza, CE, Brasil \\ ${ }^{3}$ Departamento de Farmacologia, Faculdade de Medicina de Ribeirão Preto, \\ Universidade de São Paulo, Ribeirão Preto, SP, Brasil
}

Correspondence
R.A. Ribeiro
Departamento de Fisiologia e
Farmacologia
Faculdade de Medicina, UFC
Rua Coronel Nunes de Melo, 1127
$60430-270$ Fortaleza, CE
Brasil
E-mail: ribeiror@ufc.br
Research supported by CNPq.
Publication supported by FAPESP.
$\ldots . . . . . . . . . . . .$.
Received July 18,2005
Accepted July 4,2006
$\ldots \ldots \ldots . . . . . . . . . . .$.

\section{Correspondence}

Farmacologia

Faculdade de Medicina, UFC

Rua Coronel Nunes de Melo, 1127

Brasil

Accepted July 4, 2006

\begin{abstract}
Acrolein is a urinary metabolite of cyclophosphamide and ifosfamide, which has been reported to be the causative agent of hemorrhagic cystitis induced by these compounds. A direct cytotoxic effect of acrolein, however, has not yet been demonstrated. In the present study, the effects of intravesical injection of acrolein and mesna, the classical acrolein chemical inhibitor, were evaluated. Male Swiss mice weighing 25 to $35 \mathrm{~g}$ ( $\mathrm{N}=6$ per group) received saline or acrolein $(25,75,225 \mu \mathrm{g})$ intravesically $3,6,12$, and $24 \mathrm{~h}$ before sacrifice for evaluation of bladder wet weight, macroscopic and histopathological changes by Gray's criteria, and 3 and $24 \mathrm{~h}$ for assessment of increase in vascular permeability. In other animals, mesna was administered intravesically $(2 \mathrm{mg})$ or systemically $(80 \mathrm{mg} / \mathrm{kg}) 1 \mathrm{~h}$ before acrolein. Intravesical administration of acrolein induced a dose- and timedependent increase in vascular permeability and bladder wet weight (within 3 h: 2.2- and 21-fold increases in bladder wet weight and Evans blue dye exuded, respectively, at doses of $75 \mu \mathrm{g} /$ bladder), as confirmed by Gray's criteria. Pretreatment with mesna (2-mercaptoethanesulfonic acid), which interacts with acrolein resulting in an inactive compound, inhibited all changes induced by acrolein. Our results are the first demonstration that intravesical administration of acrolein induces hemorrhagic cystitis. This model of acrolein-induced hemorrhagic cystitis in mice may be an important tool for the evaluation of the mechanism by which acrolein induces bladder lesion, as well as for investigation of new uroprotective drugs.
\end{abstract}

Key words - Acrolein

- Bladder

- Hemorrhagic cystitis

- Mesna

\section{Introduction}

Ifosfamide (IFS) and cyclophosphamide (CYP) are oxazaphosphorine-alkylating agents with a broad spectrum of antineoplastic activity. These drugs are also used as immunosuppressors in non-neoplastic diseases, such as nephrotic syndrome, systemic lupus erythematosus and rheumatoid arthritis (1). Since these agents are prodrugs, they require metabolism in the liver by cytochrome P450 mixed-function oxidase enzymes to mustards, which are the active alkylating compounds. Acrolein (ACR) is their urinary metabolite, which appears to be urotoxic (2).

Hemorrhagic cystitis (HC) is a common 
side effect that limits the use of IFS and CYP (3). Both alkylating agents induce HC, but the incidence of this side effect is higher with IFS treatment (4). The cause of bladder damage appears to be related to ACR. It has been proposed that urothelial damage occurs by direct contact with ACR. This damage is followed by bladder edema, ulceration, neovascularization, hemorrhage, and necrosis (5).

Mesna (2-mercaptoethanesulfonic acid), a thiol compound, was studied in clinical trials as a systemic uroprotective agent in the late 1970's and became the drug of choice for this purpose within a short period of time (6). Systemic administration of mesna results in regional detoxification of the urinary system $(7,8)$. The interaction between ACR and mesna results in an inactive compound, an inert thioether, which passes innocuously through urine and does not induce any damage to the uroepithelium (9).

We have demonstrated that cytokines such as tumor necrosis factor (TNF)- $\alpha$ and interleukin (IL)-1ß and nitric oxide (NO) are crucial mediators involved in the inflammatory events, including urothelial damage and hemorrhage associated with IFS- and CYPinduced HC (10-12).

It is widely accepted that ACR is the metabolite that causes HC induced by oxazaphosphorine (5). However, most of the studies that support this conclusion were performed by injecting CYP and IFS systemically. No systematic studies have been reported on the potential urotoxic effect of ACR administered directly into the bladder. In the present study, we investigated whether intravesical injection of ACR induces $\mathrm{HC}$ in mice and whether mesna, a thiol compound, prevents this process. ACR was observed to induce a dose- and time-dependent $\mathrm{HC}$ which is inhibited by the co-administration of mesna, a compound clinically used to prevent $\mathrm{HC}$ in patients undergoing CYP and IFS treatments. These results confirm that ACR causes HC and suggest that ACR-in- duced $\mathrm{HC}$, in mice, could be a simple and useful model for the evaluation of new uroprotective drugs.

\section{Material and Methods}

\section{Animals}

Male Swiss mice weighing 25 to $35 \mathrm{~g}$ were kept in appropriate cages in temperature-controlled rooms, receiving food ad libitum, but without access to drinking water during the final $18 \mathrm{~h}$ before the experiments. All experimental protocols were approved by the local Animal Care and Use Committee.

\section{Drugs}

Acrolein was obtained from Sigma-Aldrich (St. Louis, MO, USA) and mesna (Mitexan ${ }^{\circledR}$ ) and ifosfamide were from Asta Medica (São Paulo, SP, Brazil). All other reagents were from Sigma (St. Louis, MO, USA).

\section{Induction of cystitis}

A small midline abdominal incision was made in chloral hydrate-anesthetized mice $(400 \mathrm{mg} / \mathrm{kg})$ and $0.2 \mathrm{~mL}$ ACR $(25,75$, and $225 \mu \mathrm{g}$ ) or saline (control) were injected into the bladder lumen through a 33-gauge needle passed through the bladder wall. After the injection, the abdominal wall was sutured with 3-0 cotton thread (Figure 1). At different times thereafter, the animals were sacrificed by cervical dislocation, and their bladders were removed by careful dissection, emptied of urine, and evaluated for the parameters described below.

\section{Measurement of vesical edema}

Vesical edema was quantified either as an increase in bladder wet weight (BWW) (in $\mathrm{mg}$ ), reported as mean $\pm \mathrm{SEM} / 20 \mathrm{~g}$ of body weight or by determination of vesical 
vascular permeability, quantified by Evans blue dye extravasation. Evans blue $(25 \mathrm{mg} /$ $\mathrm{kg}$ ) was administered intravenously via the retro-orbital plexus $30 \mathrm{~min}$ before animal sacrifice. The bladders were dissected and placed in glass tubes containing $1 \mathrm{~mL}$ formamide. The tubes were then incubated at $56^{\circ} \mathrm{C}$ overnight. The absorbance of the extracted dye was measured at $600 \mathrm{~nm}$ and the results are reported as the mean \pm SEM amount (in $\mu \mathrm{g}$ ) of Evans blue per bladder, based on a standard curve of Evans blue.

\section{Macroscopic and microscopic evaluation}

Bladders were excised, freed from surrounding connective tissue, and examined grossly for edema and hemorrhage. A pathologist performed the histological examination in a single-blind fashion. Edema, bleeding and histological changes were evaluated according to the criteria of Gray et al. (13) as follows. Edema was considered to be severe $(3+)$ when fluid was seen externally and internally on the wall of the bladder, moderate (2+) when confined to the internal mucosa, mild $(1+)$ when normal to moderate, and absent (0). Hemorrhage was scored as follows: (3+), intravesical clots; $(2+)$, mucosal hematomas; $(1+)$, telangiectasia or dilatation of the bladder vessels; (0), normal. Histopathology was scored as follows: (0), normal epithelium and absence of inflammatory cell infiltration and ulceration; (1), mild changes involving reduction of epithelial cells, flattening with submucosal edema, mild hemorrhage and few ulcerations; (2), severe changes including mucosal erosions, inflammatory cell infiltration, fibrin deposition, hemorrhage, and multiple ulcerations. The semi-quantitative macroscopic and microscopic observations are reported as medians and range.

Effect of mesna on acrolein-induced hemorrhagic cystitis

The animals received the classic uropro- tector, mesna $(80 \mathrm{mg} / \mathrm{kg}$, intraperitoneal, ip $)$ $1 \mathrm{~h}$ before the injection of ACR (75 $\mu \mathrm{g}$, intravesical, ive). Their bladders were evaluated 3 and $24 \mathrm{~h}$ after the induction of cystitis, as described above. In another set of experiments, mesna (2 mg; 9-fold ACR molar concentration) was administered simultaneously with ive ACR $(75 \mu \mathrm{g})$ and cystitis was evaluated using the same parameters and at the same times.

\section{Statistical analysis}

Data were submitted to analysis of variance (ANOVA) followed by the Bonferroni test for the analysis of BWW and vesical vascular permeability. The Kruskal-Wallis and Dunn tests were used for macroscopic and microscopic analysis to compare medians. The level of significance was set at $\mathrm{P}<$ 0.05 .

\section{Results}

As illustrated in Figure 2, intravesical
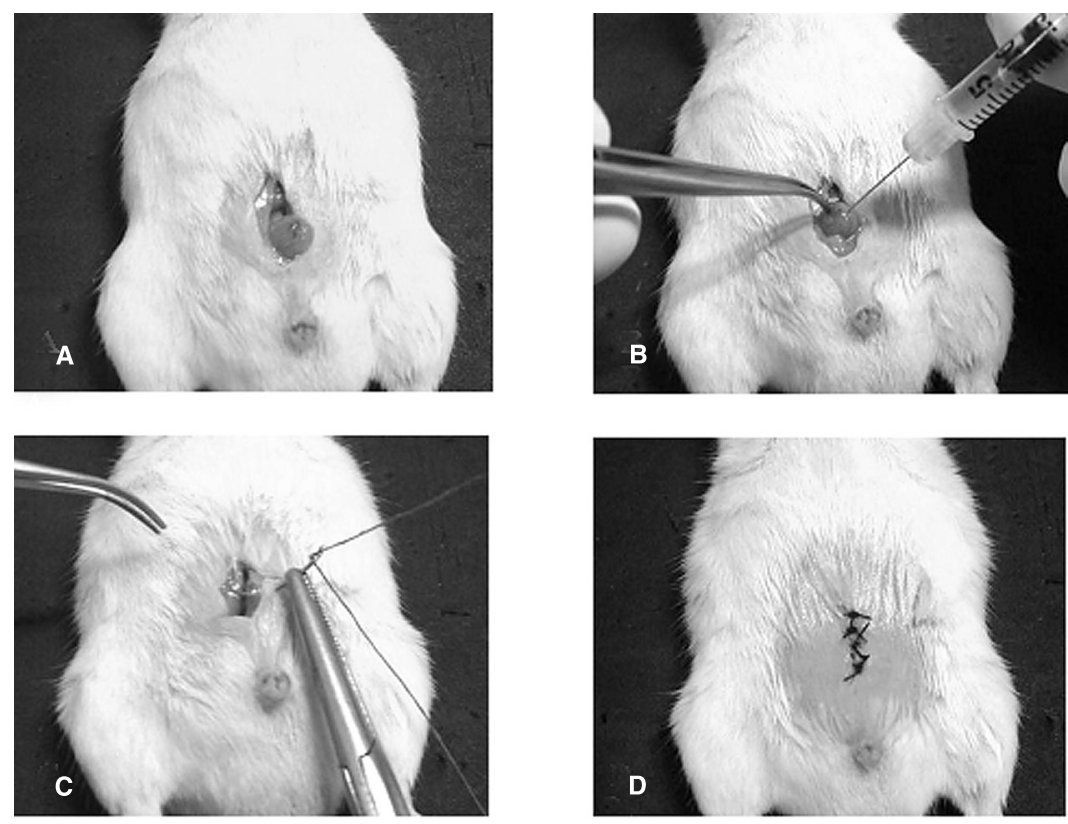

Figure 1. Surgical method for acrolein-induced hemorrhagic cystitis in mice. $A$, Exposure of the bladder; $B$, intravesical injection of acrolein; $C$, suture of the abdominal wall with a 3-0 cotton thread; $D$, sutured abdominal wall. 
injection of ACR (25 to $225 \mathrm{~g} /$ bladder) induced a dose-dependent increase in both BWW and plasma leakage within $3 \mathrm{~h}$, with significant differences at doses of $75 \mu \mathrm{g} /$ bladder (2.2- and 21-fold increases in BWW

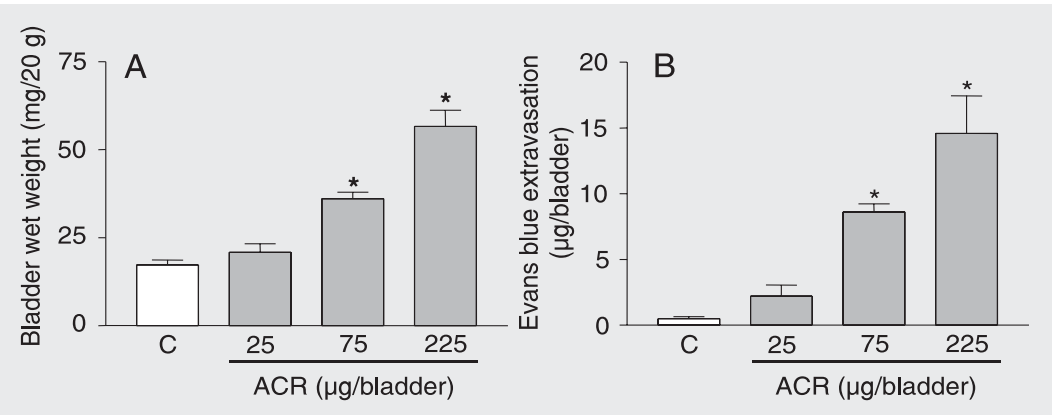

Figure 2. Dose-dependent increase in bladder wet weight and Evans blue extravasation induced by intravesically administered acrolein (ACR). Bladder wet weight (A) and Evans blue extravasation (B), in untreated animals (C, control) and in animals injected intravesically $3 \mathrm{~h}$ earlier with acrolein $(25,75,225 \mu \mathrm{g} /$ bladder $)$. Data are reported as means \pm SEM ( $\mathrm{N}=$ 6). ${ }^{*} \mathrm{P}<0.05$ compared with control (C) (ANOVA and Bonferroni test).

Figure 3. Kinetics of the increase in bladder wet weight after injection of acrolein ( $75 \mu \mathrm{g} / \mathrm{bladder})$. The dashed line indicates the value of bladder wet weight of the control group not treated with acrolein. Data are reported as the mean \pm SEM of bladder wet weight $(\mathrm{mg} / 20 \mathrm{~g})$ for 6 animals/ group. ${ }^{*} \mathrm{P}<0.05$ compared with control (ANOVA and Bonferroni test).

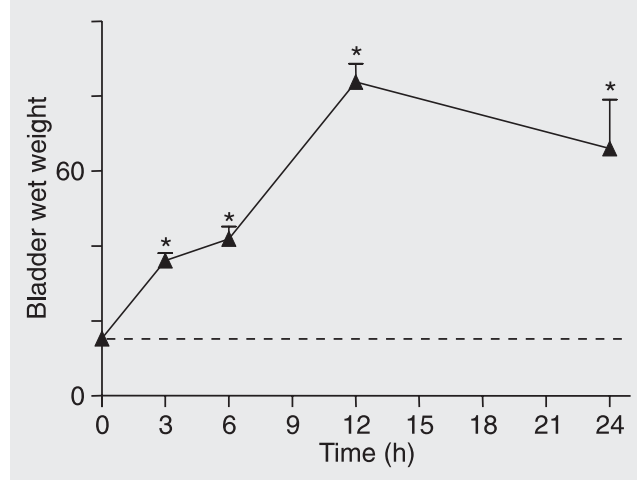

Table 1. Time course of macroscopic and microscopic changes after intravesical injection of acrolein $(75 \mu \mathrm{g} / \mathrm{bladder})$.

\begin{tabular}{clcc}
\hline Time & \multicolumn{2}{c}{ Macroscopic analysis } & Microscopic analysis \\
\cline { 2 - 3 } & Edema & Hemorrhage & \\
\hline Control & $0(0-0)$ & $0(0-0)$ & $0(0-0)$ \\
$3 \mathrm{~h}$ & $2(2-3)^{*}$ & $3(2-3)^{*}$ & $2(1-2)^{\star}$ \\
$6 \mathrm{~h}$ & $2(2-3)^{*}$ & $2(1-2)^{*}$ & $2(2-2)^{*}$ \\
$12 \mathrm{~h}$ & $2(1-3)^{*}$ & $2(0-2)^{*}$ & $2(1-2)^{*}$ \\
$24 \mathrm{~h}$ & $2(1-3)^{*}$ & $3(2-3)^{*}$ & $2(2-2)^{*}$
\end{tabular}

The results are reported as median and range within parentheses $(N=6)$. ${ }^{*} P<0.05$ compared to the control group which was not treated with acrolein (KruskalWallis and Dunn tests). and Evans blue dye exuded, respectively) and $225 \mathrm{~g} /$ bladder (3.4- and 37-fold increases in BWW and Evans blue dye exuded, respectively). The administration of ACR (75 $\mu \mathrm{g} / \mathrm{bladder}$ ) induced a time-dependent increase of BWW which was significant as early as $3 \mathrm{~h}(139.44 \%)$ after induction of cystitis, reaching a peak at $12 \mathrm{~h}$ after ACR administration $(353.33 \%)$ and decreasing thereafter, but which continued to be significant up to 24 h (239.77\%; Figure 3). According to Gray's score, ACR ( $75 \mu \mathrm{g} /$ bladder) induced a time-dependent increase in macroscopic and microscopic scores which were significant at $3 \mathrm{~h}$, with a peak occurring at 24 h (Table 1).

ACR-evoked increases in BWW and Evans blue extravasation, observed at $3 \mathrm{~h}$ after ACR injection, were significantly inhibited by systemic or local (ive) pretreatment with mesna $(80 \mathrm{mg} / \mathrm{kg}$, ip , and $2 \mathrm{mg} /$ bladder, ive, respectively; Figure 4). The same was observed $24 \mathrm{~h}$ after ACR injection (data not shown).

Cystitis observed $3 \mathrm{~h}$ after ACR administration was characterized macroscopically by the presence of severe edema, receiving a score of 2 (2-3), and by extensive hemorrhage with mucosal hematomas, receiving a score of 2 (1-3), and was significantly $(\mathrm{P}<$ $0.05)$ different from the control group which received a score of $0(0-0)$ for edema and hemorrhage. The bladders evaluated after $24 \mathrm{~h}$ presented severe edema, receiving a score of 3 (2-3), and mucosal hematomas and intravesical clots, receiving a score of 2 (2-3). Macroscopic analysis of the bladder at 3 and $24 \mathrm{~h}$ after ACR injection revealed that the mesna pretreatments (ip and ive) significantly reduced $(\mathrm{P}<0.05)$ the parameters analyzed (Table 2). According to Gray's histopathological criteria, when compared with normal bladders, microscopic analysis of the bladders of mice injected $3 \mathrm{~h}$ before with $75 \mu \mathrm{g} / \mathrm{bladder}$ of ACR revealed extensive cystitis characterized by acute inflammation with vascular congestion, edema, 
hemorrhage with fibrin deposition, neutrophil infiltration, and epithelial denudation, receiving a score of 2 (1-2). Twenty-four hours after ACR administration the microscopic analysis was similar, but extensive hemorrhage was observed, receiving a score of 2 (2-2). These alterations were almost abolished $(\mathrm{P}<0.05)$ by treatment of the ACR-injected mice with mesna $(2 \mathrm{mg} / \mathrm{blad}$ der, ive or $80 \mathrm{mg} / \mathrm{kg}$, ip). The scores of Gray's parameters (median and range) are shown in Table 2.

\section{Discussion}

It is accepted that HC, a side effect observed in patients under CYP and IFS treatment, is caused by the urinary metabolite, ACR (5). Most of the studies that support this conclusion were performed by administering CYP and IFS systemically (14). However, in the current study we determined whether ive administration of ACR causes HC. ACR injected into the mouse bladder induced a dose- and time-dependent $\mathrm{HC}$ as determined by the increase in BWW and Evans blue extravasation, parameters that have been used to quantify cystitis in rats (12) and mice (15). Both parameters were already significant $3 \mathrm{~h}$ after ACR administration, peaking at $12 \mathrm{~h}$ and decreasing thereafter, with no further increase after $24 \mathrm{~h}$, suggesting that a plateau had been reached. The ACR-induced HC was confirmed by macroscopic and histopathological changes of the bladder analyzed by the Gray's criteria, which were used to quantify HC (13). The profile of HC observed after ACR administration was similar to that observed when CYP or IFS was administered to mice (15) or rats (12). This fact, taken together with the demonstration that ACR is found in the urine of humans (16) and of experimental animals treated with CYP or IFS (17), as described in the literature $(5,14,18,19)$, indicate that ACR is the urine metabolite responsible for the HC observed after oxazaphos- phorine treatment.

The macroscopic and microscopic analysis of the bladder from ACR-injected mice, revealed intense vascular congestion and edema in the early phase $(3 \mathrm{~h})$, findings which were followed by neutrophil infiltration, hemorrhage, ulceration and severe necrosis, sometimes with perforation ( $24 \mathrm{~h}$ after ACR administration). Most of these findings are also observed after CYP or IFS administration to humans (3), or to experimental animals (20).
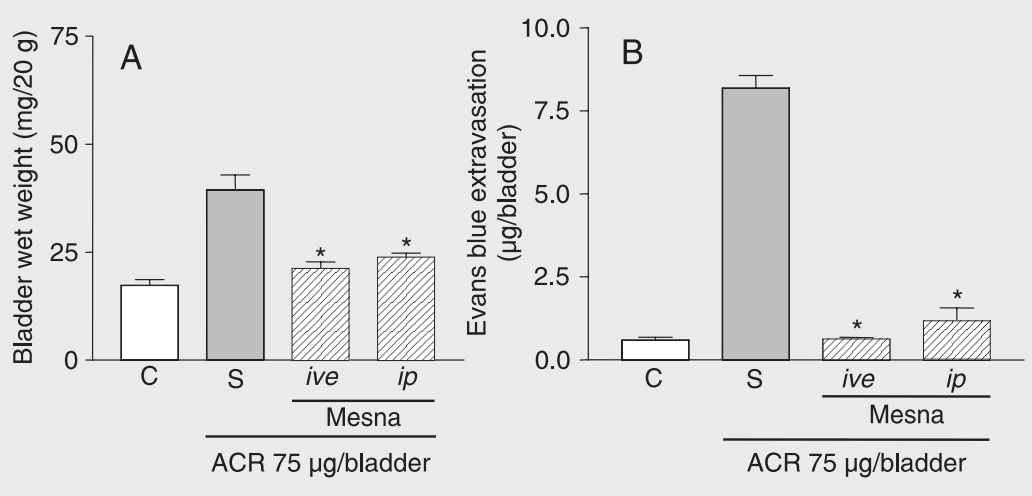

Figure 4. Effect of different routes of administration of mesna on bladder wet weight $(A)$ and Evans blue extravasation (B) in acrolein-induced hemorrhagic cystitis. Acrolein (ACR) (75 $\mu \mathrm{g} / \mathrm{bladder}$ )-induced increase in bladder wet weight and Evans blue extravasation were measured $3 \mathrm{~h}$ after the induction of cystitis in mice treated with vehicle (saline, S). Mesnatreated animals received $2 \mathrm{mg} /$ bladder mesna injected intravesically (ive) simultaneously with ACR or $80 \mathrm{mg} / \mathrm{kg}$ of mesna injected intraperitoneally (ip) $1 \mathrm{~h}$ before ACR injection. Data are reported as means \pm SEM $(N=6)$. ${ }^{*} P<0.05$ compared to saline control group ( $S$, treated with acrolein and saline) (ANOVA and Bonferroni test).

Table 2. Effect of intraperitoneally and intravesically injected mesna on the macroscopic and microscopic effects of cystitis induced by intravesical injection of acrolein.

\begin{tabular}{|c|c|c|c|c|c|c|}
\hline \multirow[t]{3}{*}{ Group } & \multicolumn{4}{|c|}{ Macroscopic analysis } & & \\
\hline & \multicolumn{2}{|c|}{ Edema } & \multicolumn{2}{|c|}{ Hemorrhage } & \multicolumn{2}{|c|}{ Microscopic analysis } \\
\hline & $3 \mathrm{~h}$ & $24 \mathrm{~h}$ & $3 \mathrm{~h}$ & $24 \mathrm{~h}$ & $3 \mathrm{~h}$ & $24 \mathrm{~h}$ \\
\hline Control & $0(0-0)$ & $0(0-0)$ & $0(0-0)$ & $0(0-0)$ & $0(0-0)$ & $0(0-0)$ \\
\hline ACR & $2(2-3)$ & $3(2-3)$ & $2(1-3)$ & $2(2-3)$ & $2(1-2)$ & $2(2-2)$ \\
\hline $\mathrm{ACR}+$ mesna ive & $0(0-1)^{*}$ & $0(0-1)^{*}$ & $0(0-1)^{\star}$ & $0(0-1)^{*}$ & $0(0-1)^{*}$ & $0(0-1)^{*}$ \\
\hline $\mathrm{ACR}+$ mesna ip & $1(0-1)^{*}$ & $0(0-1)^{*}$ & $0(0-1)^{*}$ & $1(0-1)^{*}$ & $0(0-2)^{*}$ & $0(0-1)^{*}$ \\
\hline
\end{tabular}

Acrolein (ACR, $75 \mu \mathrm{g} / \mathrm{bladder}$ )-induced macroscopic and microscopic alterations were evaluated after 3 and $24 \mathrm{~h}$. Mice treated with mesna intravesically (ive, $2 \mathrm{mg} /$ bladder) or intraperitoneally (ip, $80 \mathrm{mg} / \mathrm{kg}$ ) were evaluated at 3 or $24 \mathrm{~h}$ after ACR $(75 \mu \mathrm{g} / \mathrm{bladder}$ ) or saline (control). Data are reported as median and range within parentheses $(N=6)$. ${ }^{*} \mathrm{P}<0.05$ compared to ACR group (Kruskal-Wallis and Dunn tests). 
The mechanism by which ACR causes HC has not been fully elucidated. However, there is evidence that, after administration of CYP or IFS, ACR appears within the bladder, causing a reduction of endogenous glutathione $(21,22)$ and inducing the generation of free radicals, such as superoxide anion and hydroxyl radical, which initiate lipid peroxidation and other cell damage $(23,24)$. Recently, we demonstrated that the cytokines TNF- $\alpha$ and IL- $1 \beta$, acting by activation of the L-arginine/iNOS/NO pathway, might also play a crucial role in the geneses of pathophysiological events of $\mathrm{HC}$ observed in animals treated with CYP or IFS (10). In this context, previous reports have shown that exposure of the respiratory tract to ACR results in an increase in the production of inflammatory mediators such as eicosanoids and also causes a significant influx of neutrophils into the bronchoalveolar lavage (25). Moreover, evidence also exists that ACR increases the release of IL-8 by neutrophils (26).

In the present study, to validate the model of ACR-induced HC, the animals were treated with mesna, a classical uroprotector agent with established clinical (8) and ex- perimental efficacy $(20,27)$. The increase in BWW and Evans blue extravasation was blocked by pretreatment of the mice with mesna, regardless of local or systemic administration. Furthermore, mesna also blocked the bladder's macroscopic and microscopic changes induced by ive administration of ACR. There is evidence that ACR reacts with mesna producing an inert thioether that is eliminated in the urine (19). Thus, in this model, as is also the case for humans or animals treated with oxazaphosphorine (20), mesna presented its uroprotective effect when administered systemically or locally.

Our results are the first demonstration that intravesical administration of ACR induces HC. This model of ACR-induced HC in mice may be an important tool for the evaluation of the mechanism by which ACR induces bladder lesion, as well as, for investigation of new uroprotective drugs.

\section{Acknowledgments}

The authors gratefully acknowledge M. Silvandira F. Pinheiro, J. Ivan R. Sousa and Sergio R. Rosas for technical assistance.

\section{References}

1. Calabresi P, Chabner BA. Antineoplastic agents. In: Goldman AF, Rall TW, Niss AS, Taylor P (Editors), The pharmacological basis of therapeutics. Singapore: McGraw-Hill, 1992.

2. Dechant KL, Brogden RN, Pilkington T, Faulds D. Ifosfamide/mesna. A review of its antineoplastic activity, pharmacokinetic properties and therapeutic efficacy in cancer. Drugs 1991; 42: 428-467.

3. Stillwell TJ, Benson RC Jr. Cyclophosphamide-induced hemorrhagic cystitis. A review of 100 patients. Cancer 1988; 61: 451-457.

4. Ratliff TL, Williams RD. Hemorrhagic cystitis, chemotherapy, and bladder toxocity. J Urol 1998; 159: 1044.

5. Cox PJ. Cyclophosphamide cystitis - identification of acrolein as the causative agent. Biochem Pharmacol 1979; 28: 2045-2049.

6. Katz A, Epelman S, Anelli A, Gorender EF, Cruz SM, Oliveira RM, et al. A prospective randomized evaluation of three schedules of mesna administration in patients receiving an ifosfamide-containing chemotherapy regimen: sustained efficiency and simplified administration. J Cancer Res Clin Oncol 1995; 121: 128-131.

7. Elias AD, Eder JP, Shea T, Begg CB, Frei E III, Antman KH. Highdose ifosfamide with mesna uroprotection: a phase I study. $J$ Clin
Oncol 1990; 8: 170-178.

8. Scheulen ME, Niederle N, Bremer K, Schutte J, Seeber S. Efficacy of ifosfamide in refractory malignant diseases and uroprotection by mesna: results of a clinical phase II-study with 151 patients. Cancer Treat Rev 1983; 10 (Suppl A): 93-101.

9. Brock N, Pohl J. The development of mesna for regional detoxification. Cancer Treat Rev 1983; 10 (Suppl A): 33-43.

10. Ribeiro RA, Freitas HC, Campos MC, Santos CC, Figueiredo FC, Brito GA, et al. Tumor necrosis factor-alpha and interleukin-1beta mediate the production of nitric oxide involved in the pathogenesis of ifosfamide induced hemorrhagic cystitis in mice. J Urol 2002; 167: 2229-2234.

11. Gomes TN, Santos CC, Souza-Filho MV, Cunha FQ, Ribeiro RA. Participation of TNF-alpha and IL-1 in the pathogenesis of cyclophosphamide-induced hemorrhagic cystitis. Braz J Med Biol Res 1995; 28: 1103-1108.

12. Souza-Fiho MV, Lima MV, Pompeu MM, Ballejo G, Cunha FQ, Ribeiro RA. Involvement of nitric oxide in the pathogenesis of cyclophosphamide-induced hemorrhagic cystitis. Am J Pathol 1997; 150: 
247-256.

13. Gray KJ, Engelmann UH, Johnson EH, Fishman IJ. Evaluation of misoprostol cytoprotection of the bladder with cyclophosphamide (Cytoxan) therapy. J Urol 1986; 136: 497-500.

14. Brock N, Stekar J, Pohl J, Niemeyer U, Scheffler G. Acrolein, the causative factor of urotoxic side-effects of cyclophosphamide, ifosfamide, trofosfamide and sufosfamide. Arzneimittelforschung 1979; 29: 659-661.

15. Assreuy AM, Martins GJ, Moreira ME, Brito GA, Cavada BS, Ribeiro RA, et al. Prevention of cyclophosphamide-induced hemorrhagic cystitis by glucose-mannose binding plant lectins. J Urol 1999; 161 : 1988-1993.

16. Al-Rawithi S, el-Yazigi A, Ernst P, Al-Fiar F, Nicholls PJ. Urinary excretion and pharmacokinetics of acrolein and its parent drug cyclophosphamide in bone marrow transplant patients. Bone Marrow Transplant 1998; 22: 485-490.

17. Shaw IC, Graham MI, McLean AE. 2-Chloroacetaldehyde: a metabolite of cyclophosphamide in the rat. Cancer Treat Rev 1983; 10 (Suppl A): 17-24.

18. Kolb NS, Hunsaker LA, Vander Jagt DL. Aldose reductase-catalyzed reduction of acrolein: implications in cyclophosphamide toxicity. Mol Pharmacol 1994; 45: 797-801.

19. Wagner T. Ifosfamide clinical pharmacokinetics. Clin Pharmacokinet 1994; 26: 439-456.

20. Morais MM, Belarmino-Filho JN, Brito GA, Ribeiro RA. Pharmacological and histopathological study of cyclophosphamide-induced hemorrhagic cystitis - comparison of the effects of dexamethasone and mesna. Braz J Med Biol Res 1999; 32: 1211-1215.

21. Pocernich CB, Cardin AL, Racine CL, Lauderback CM, Butterfield DA. Glutathione elevation and its protective role in acrolein-induced protein damage in synaptosomal membranes: relevance to brain lipid peroxidation in neurodegenerative disease. Neurochem Int 2001; 39: 141-149.

22. Nardini M, Finkelstein El, Reddy S, Valacchi G, Traber M, Cross CE, et al. Acrolein-induced cytotoxicity in cultured human bronchial epithelial cells. Modulation by alpha-tocopherol and ascorbic acid. Toxicology 2002; 170: 173-185.

23. Adams JD Jr, Klaidman LK. Acrolein-induced oxygen radical formation. Free Radic Biol Med 1993; 15: 187-193.

24. Patel JM. Stimulation of cyclophosphamide-induced pulmonary microsomal lipid peroxidation by oxygen. Toxicology 1987; 45: 79-91.

25. Leikauf GD. Mechanisms of aldehyde-induced bronchial reactivity: role of airway epithelium. Res Rep Health Eff Inst 1992; 1-35.

26. Mio T, Romberger DJ, Thompson AB, Robbins RA, Heires A, Rennard SI. Cigarette smoke induces interleukin-8 release from human bronchial epithelial cells. Am J Respir Crit Care Med 1997; 155: $1770-1776$.

27. Themann H, Oberdorf E, Brock N, Pohl J. Electron microscopic investigations of the cyclophosphamide-induced lesions of the urinary bladder of the rat and their prevention by mesna. Urol Int 1987; 42: 37-43. 